\title{
ESTUDO DA VIABILIDADE ECONÔMICA DE CICLOVIAS COM PAINÉIS FOTOVOLTAICOS NO CENÁRIO BRASILEIRO
}

\section{ARTIGO ORIGINAL}

COTTA, Carolina Guerra ${ }^{1}$

SALVI, Levi ${ }^{2}$

COTTA, Carolina Guerra. SALVI, Levi. Estudo da viabilidade econômica de ciclovias com painéis fotovoltaicos no cenário brasileiro. Revista Científica Multidisciplinar Núcleo do Conhecimento. Ano 04, Ed. 08, Vol. 02, pp. 18-38. Agosto de 2019. ISSN: 2448-0959, Link de acesso: https://www.nucleodoconhecimento.com.br/engenharia-civil/paineisfotovoltaicos

\section{RESUMO}

Com o aumento dos congestionamentos em médios e grandes centros, tem-se buscado cada vez mais soluções práticas e sustentáveis para a mobilidade urbana. Uma solução que tem obtido sucesso em diversos locais do mundo é a utilização da bicicleta como meio de transporte. Paralelo a isso, o aumento da emissão de gases e da poluição do planeta, tem forçado governos a buscar soluções cada vez mais sustentáveis para a geração de energia que será consumida em seus países. No presente artigo é apresentado um projeto com estudo de caso de uma ciclovia que fará uso de painéis solares em seu piso, com o objetivo de gerar energia para sua própria iluminação e arredores, bem como avaliar a viabilidade econômica deste projeto e o tempo de retorno financeiro para o investimento inicial.

Palavras-chave: ciclovia, painel solar, energia solar, sustentabilidade, ecoeficiência.

${ }^{1}$ Graduanda em Engenharia Civil.

2 Doutor em Engenharia. 


\section{INTRODUÇÃO}

É relevante o número de planos urbanos de desenvolvimento sustentável que visam reduzir o número de veículos automotores e expandir os modais a pé e de bicicleta. Com isso, surge o redescobrimento da bicicleta e, com ele, o aumento no número de ciclovias e a aparição de bicicletas modernas, motorizadas, elétricas, e até mesmo produzidas com materiais ecologicamente corretos.

Paralelo a isso, o conceito de energia limpa está cada vez mais em foco em discussões dos grandes encontros governamentais. Foi na Conferência das Nações Unidas sobre o Meio Ambiente Humano, realizada em Estocolmo (1972), que se falou pela primeira vez a respeito da necessidade de "defender e melhorar o ambiente humano para as atuais e futuras gerações", isto é, planejar e desenvolver ações sustentáveis. $O$ assunto, no entanto, permaneceu nebuloso até o acontecimento da ECO-92, no Rio de Janeiro (1992). Foi quando os termos "desenvolvimento" e "sustentável" passaram a ser tratados de forma conjunta. O evento, então, deixou como legado o conceito de que "o desenvolvimento que atende as necessidades do presente não podia comprometer a possibilidade das futuras gerações de atenderem as suas próprias necessidades".

A junção do aumento significativo de ciclistas com os estudos latentes a respeito de energias renováveis é capaz de gerar o questionamento sobre a viabilidade de uma ciclovia composta de painéis solares em seu piso.

\subsection{BICICLETA COMO MEIO DE TRANSPORTE}

BOARETO (2010), afirma que o aumento exponencial da utilização de automóveis dos últimos anos impacta a sociedade em dois âmbitos: individual e social. No primeiro, podemos verificar o aumento de tempo no traslado intramunicipal. Isto é, para que um usuário se desloque nas grandes cidades, mesmo que pequenas distâncias, ele deverá reservar uma considerável parte de seu dia para o tempo em trânsito. Já no segundo âmbito, encontramos o foco majoritário das discussões da atualidade: a poluição sonora e do ar, que afeta diretamente a qualidade de vida da comunidade. 
De acordo com o International Transport Forum da Organization for Economic Cooperation and Development - OECD (2017), os meios de transporte ocupam as primeiras colocações entre os principais responsáveis pelas emissões de $\mathrm{CO} 2$ por utilização de combustíveis fósseis. A OECD ainda afirma que há indicadores que apontam para um aumento de até duas vezes nas emissões ligadas a atividades de transporte nos próximos trinta anos em todo o mundo, mesmo diante de uma meta de redução das emissões globais de carbono da ordem de 50\% até 2050.

Como é possível observar na Figura 1, apresentado no Relatório Geral de Sistemas de Informações da Mobilidade Urbana da Associação Nacional de Transportes Públicos (ANTP), mais de $40 \%$ da população de regiões metropolitanas brasileiras realiza a sua mobilidade a pé ou de bicicleta. Ainda, de acordo com a pesquisa Origem e Destino de São Paulo, realizada em 2007, se forem consideradas apenas as viagens curtas na região metropolitana de São Paulo, ou seja, as de até aproximadamente 15 minutos, esse número sobe para $70 \%$.

Conclui-se, então, que "há uma grande concentração de trajetos longos feitos a pé que poderiam ser feitos de bicicleta, mas não o são, principalmente, pela inexistência de ciclovias e pela falta de uma política de incentivo ao uso da bicicleta e da integração desta ao transporte coletivo". (BOARETO, 2010. p.14) 
Figura 1. Divisão modal 2007 - Regiões Metropolitanas do Brasil.

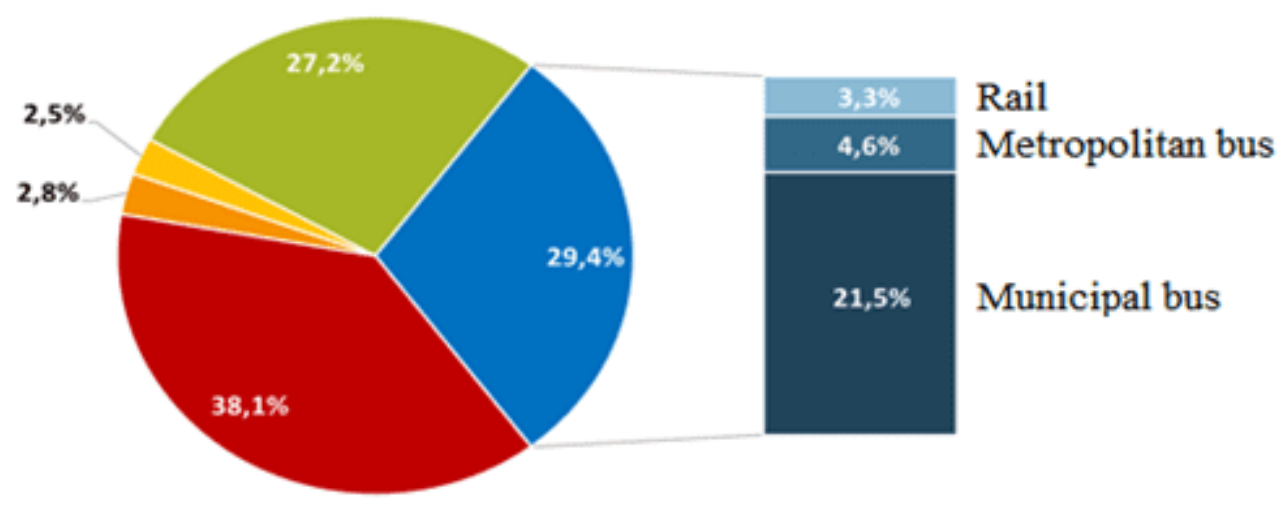

$\square$ On foot $\square$ Bike $\square$ Motorcycle $\square$ Car $\square$ Collective transportation

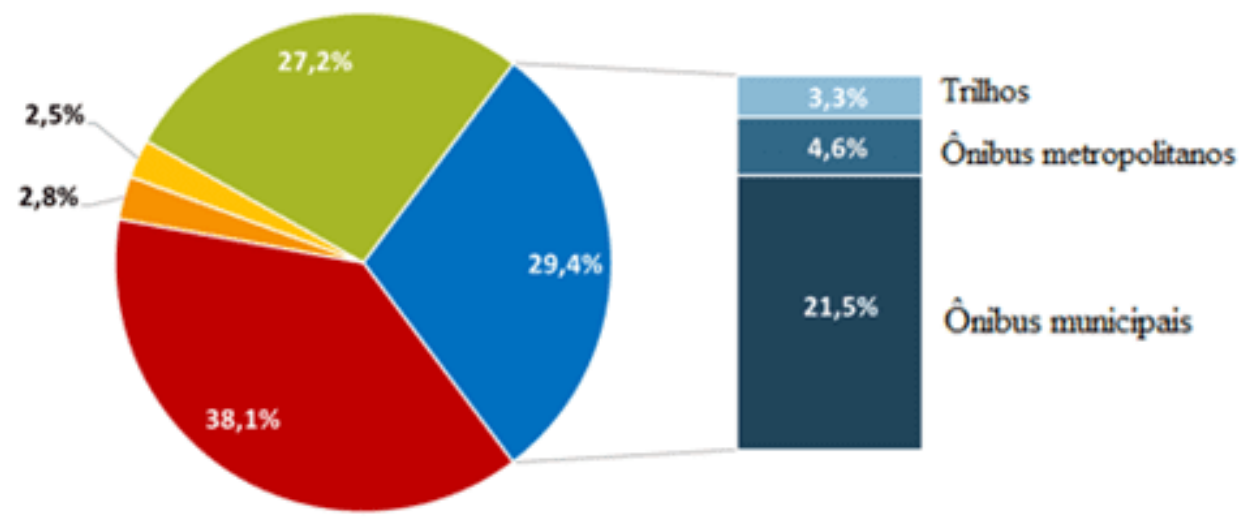

Fonte: BOARETO (2010).

Desta forma, a bicicleta surge como alternativa das políticas públicas para a mobilidade urbana sustentável, apresentando características eficientes nos cenários econômico e de mobilidade urbana; e como alternativa de empreendimento, visto que paulatinamente encontramos o incentivo da utilização de bicicletas, como novas ciclovias em grandes metrópoles, aluguéis de bicicletas a preços acessíveis e bicicletas elétricas motorizadas comercializadas ao grande público. 


\subsection{O POTENCIAL DE ENERGIA SOLAR}

O desempenho do Sol em relação à sua potência de radiação é excepcional quando comparado com todas as outras fontes de energia. Como é possível ver na Figura 2, o diâmetro dos círculos corresponde ao potencial de energia disponível no planeta para cada tipo de produção. A Ecomontes (2017) mostra que é correto afirmar, portanto, que o Sol é capaz de produzir 250 vezes mais energia do que as águas utilizadas em energia hídrica. Além disso, mesmo quando somados todos os potenciais energéticos, eles não superam o possível potencial de energia solar.

Figura 2. Potencial das Energias no Mundo.

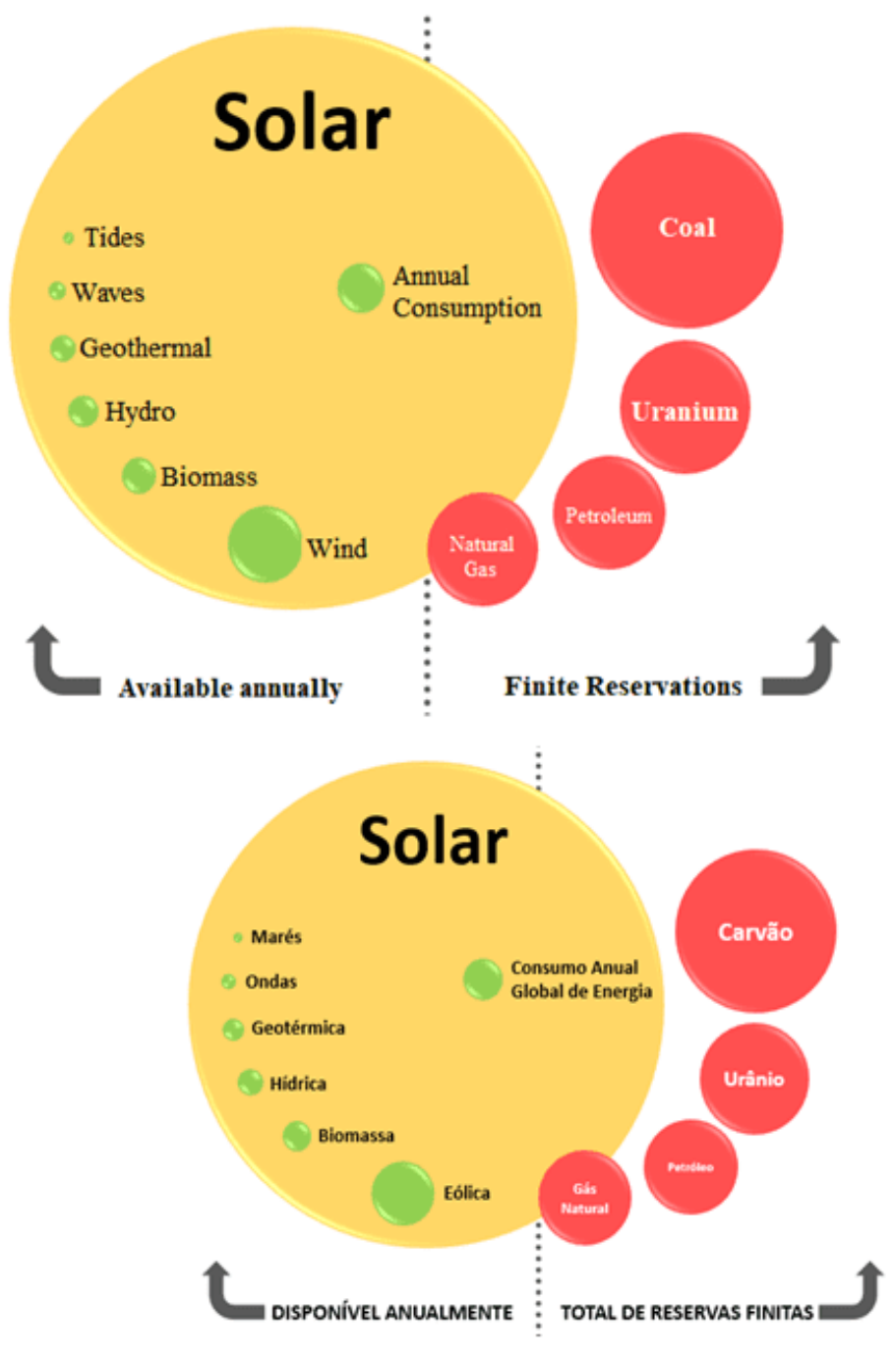

Fonte: Ecomontes (2017). 
Ela é, portanto, o tipo de energia limpa com maior potencial futuro para produção em massa de painéis solares (redução no custo de produção) e mão de obra especializada (redução no custo de instalação e manutenção), visto que as constantes adversidades ambientais causadas pela utilização de energias não renováveis, aliadas ao esgotamento dessas fontes, têm despertado o interesse e adesão de fontes alternativas de energia. Dentre elas, os painéis fotovoltaicos, que se caracterizam pela geração de energia através da captação de luz solar.

\subsection{OBJETIVO}

Peter Nijkamp, economista e professor na Universidade de Vrije (Amsterdam), afirma, em sua publicação intitulada "Social Change and Sustainable Transport" (2002), que hoje trabalhamos com o "Triângulo da Sustentabilidade", que pode ser visto na Figura 3, cujo tripé é composto por Ambiental, Social e Econômico. Dentro do conceito, todos os aspectos devem interagir de forma holística para satisfazer o triângulo, que também ficou conhecido como os 3 Ps (People, Planet and Profit). Nijkamp afirma que ao preocupar-se com as três vertentes, encontra-se a chave para a sustentabilidade: o equilíbrio. 
Figura 3. Triângulo da Sustentabilidade de Peter Nijkamp.
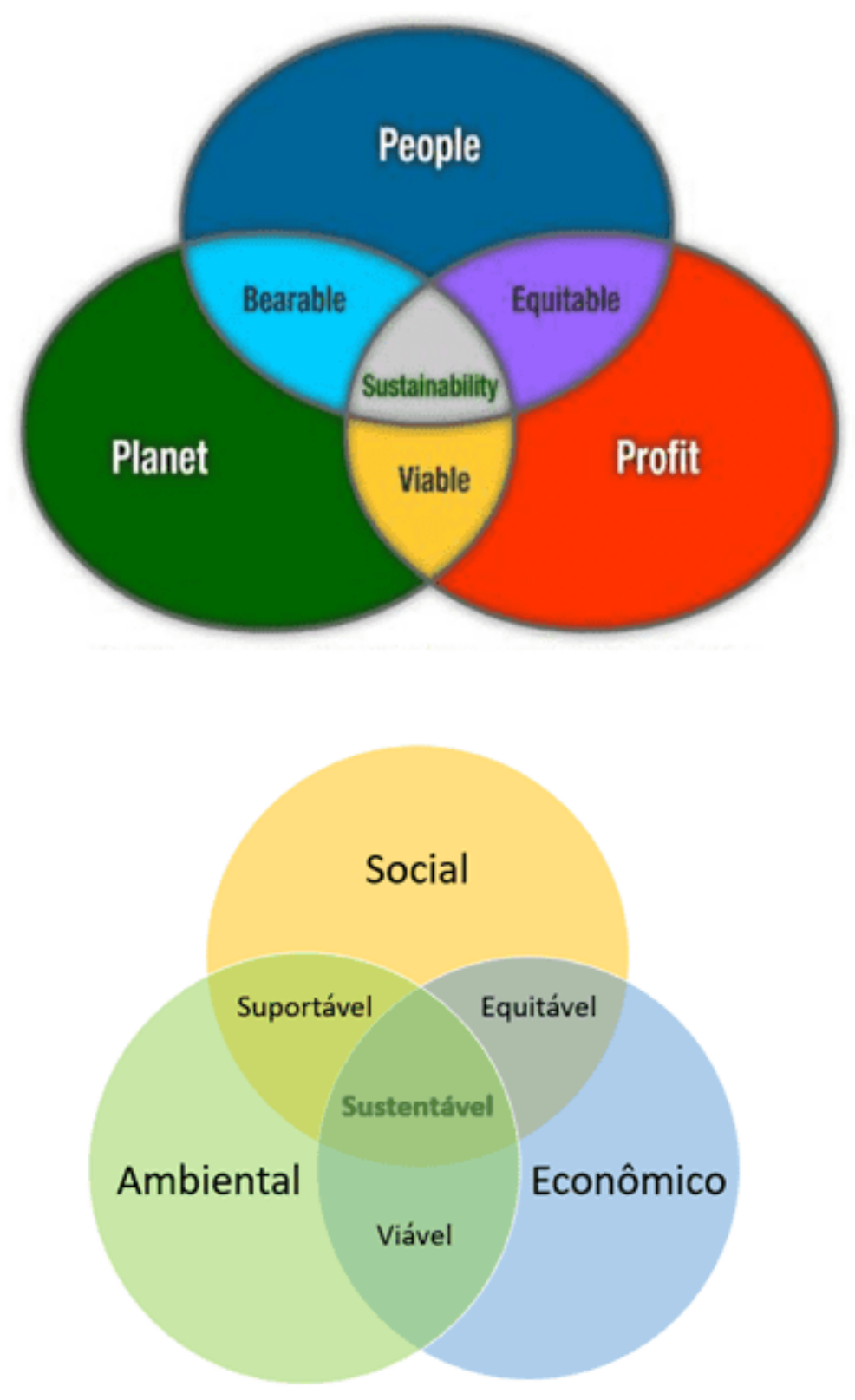

Fonte: Sustentarte.

Desta forma, esta projeção de ciclovia objetiva demonstrar um equilíbrio entre o Ambiental, o Social e o Econômico através do estudo de viabilidade de uma ciclovia, na orla de Niterói, formada por painéis fotovoltaicos, com o objetivo de geração de energia para iluminar a pista durante os períodos sem iluminação natural. 


\section{ESCOLHA DO CENÁRIO BRASILEIRO}

\subsection{A ESCOLHA DE NITERÓI/RJ}

A cidade fluminense está localizada no estado do Rio de Janeiro, próxima ao paralelo 22S, possuindo índice alto de incidência solar de acordo com a Empresa de Pesquisa Energética (EPE) e níveis de umidade média em $20 \%$. Isto significa, de forma simplificada, que a cidade possui, em média, $20 \%$ dos dias do ano chuvosos. Nos outros, a iluminação natural do Sol predomina a região. O clima quente e úmido da cidade favorece, portanto, a realização de atividades físicas ao ar livre, como caminhadas, mergulhos no mar e voltas de bicicleta pela cidade. Na Figura 4 está demonstrado os dados climáticos históricos da cidade.

Figura 4. Quadro climático da cidade de Niterói (RJ).

\begin{tabular}{|c|c|c|c|c|c|c|c|c|c|c|c|c|}
\hline & January & February & March & April & May & June & July & August & September & October & November & December \\
\hline Average temperature ${ }^{\circ} \mathrm{C}$ & 26.4 & 26.5 & 25.8 & 23.8 & 22.2 & 21.3 & 20.7 & 21.2 & 21.7 & 22.0 & 24 & 24.8 \\
\hline Minimum temperature ${ }^{\circ} \mathrm{C}$ & 22.4 & 22.5 & 21.8 & 20.2 & 18.2 & 17 & 16.4 & 16.8 & 17.8 & 10.2 & 20.3 & 21.1 \\
\hline Maximum temperature ${ }^{\circ} \mathrm{C}$ & 30.5 & 30.6 & 20.7 & 27.7 & 26.2 & 25.6 & 25.1 & 25.5 & 25.6 & 28.6 & 27.7 & 28.6 \\
\hline Average temperature ${ }^{\circ} \mathbf{F}$ & 79.5 & 79.7 & 78.4 & 75.0 & 72.0 & 70.3 & 60.3 & 70.2 & 71.1 & 73.2 & 75.2 & 76.6 \\
\hline Minimum temperature ${ }^{\circ} \mathbf{F}$ & 72.3 & 72.5 & 71.4 & 68.4 & 64.8 & 62.6 & 61.5 & 62.4 & 64.2 & 68.6 & 68.5 & 70.0 \\
\hline Maximum temperature ${ }^{\circ} \mathbf{F}$ & 86.0 & 87.1 & 85.5 & 81.0 & 70.2 & 78.1 & 77.2 & 77.8 & 78.1 & 70.0 & 81.0 & 83.5 \\
\hline Rain (mm) & 140 & 141 & 147 & 121 & 84 & 52 & 50 & 50 & 65 & 92 & 113 & 143 \\
\hline & Janeiro & Fevereiro & Março & Abril & Maio & Junho & Julho & Agosto & Setembro & Outubro & Novembro & Dezembro \\
\hline Temperatura média ( $\left.{ }^{\circ} \mathrm{C}\right)$ & 26.4 & 28.5 & 25.8 & 23.0 & 22.2 & 21.3 & 20.7 & 21.2 & 21.7 & 220 & 24 & 24.8 \\
\hline Temperatura minima ( $\left.{ }^{\circ} \mathrm{C}\right)$ & 22.4 & 22.5 & 21.8 & 20.2 & 18.2 & 17 & 16.4 & 16.8 & 17.0 & 10.2 & 20.3 & 21.1 \\
\hline $\begin{array}{l}\text { Temperatura máxima } \\
\qquad\left({ }^{\circ} \mathrm{C}\right)\end{array}$ & 30.5 & 30.6 & 20.7 & 27.7 & 28.2 & 25.6 & 25.1 & 25.5 & 25.6 & 28.6 & 27.7 & 28.6 \\
\hline Temperatura média $\left({ }^{\circ} \mathrm{F}\right)$ & 70.5 & 79.7 & 78.4 & 75.0 & 72.0 & 70.3 & 69.3 & 70.2 & 71.1 & 73.2 & 75.2 & 76.6 \\
\hline Temperatura minima $\left({ }^{\circ} \mathrm{F}\right)$ & 72.3 & 72.5 & 71.4 & 68.4 & 64.8 & 62.6 & 61.5 & 62.4 & 64.2 & 68.6 & 68.5 & 70.0 \\
\hline $\begin{array}{c}\text { Temperatura máxima } \\
\left({ }^{\circ} \mathrm{F}\right)\end{array}$ & 86.0 & 87.1 & 85.5 & 81.0 & 79.2 & 78.1 & 77.2 & 77.9 & 78.1 & 79.0 & 81.0 & 83.5 \\
\hline Chuva (mm) & 148 & 141 & 147 & 121 & 84 & 52 & 50 & 50 & 65 & 92 & 113 & 143 \\
\hline
\end{tabular}

Fonte: Empresa de Pesquisa Energética. 
Em 2017, Niterói foi avaliada como a melhor cidade fluminense e a $7^{\underline{a}}$ melhor cidade do país no quesito "qualidade de vida", pois possui o $7^{\circ}$ maior Índice de Desenvolvimento Humano (IDH) do país, com um valor de 0,837 - considerado muito alto pelo Atlas do Desenvolvimento Humano do Programa das Nações Unidas para o Desenvolvimento - PNUD (2017).

No primeiro semestre de 2017, a consultoria Macroplan realizou uma auditoria para avaliar quais seriam as 100 melhores cidades do país para se viver. Dentre os mais de 5.500 municípios brasileiros, Niterói ocupou a 25ª posição, sendo a melhor cidade do estado do Rio de Janeiro na lista.

O Índice FIRJAN (Federação das Indústrias do Estado do Rio de Janeiro) de Gestão Fiscal (IFGF), divulgado pelo Sistema FIRJAN (2016) revela que Niterói foi a única cidade fluminense a apresentar gestão fiscal de excelência. "O município obteve 0,8384 no IFGF e é o sexto com melhor desempenho em todo o país" é o que afirma a Secretaria do Tesouro Nacional (2017).

Ainda, em 2017, Niterói foi eleita pela Fundação Getúlio Vargas (FGV) e pelo Instituto de Longevidade Mongeral Aegon (ILMA) como a melhor cidade do Rio de Janeiro e a quarta melhor cidade do país em qualidade de vida para idosos. De acordo com a pesquisa, divulgada no jornal O Fluminense, a cidade possui áreas de convivência para idosos, é pontual em segurança próximo a áreas de população idosa, apresenta opções de vida diurna, vespertina e noturna para os cidadãos com mais de 65 anos e, por fim, apresenta grande variedade de opção para deslocamento desta parcela da sociedade, incluindo uma vasta quantia de ciclovias unindo bairros como Icaraí, Jardim Icaraí, Santa Rosa e São Francisco, locais estes onde o público idoso está predominantemente localizado.

Por fim, a atual gestão da cidade possui um programa intitulado "Niterói de Bicicleta", sendo um dos 32 projetos definidos no plano estratégico municipal "Niterói que Queremos". Pensado como uma resposta aos desafios relacionados à mobilidade, ao meio ambiente e, de uma maneira mais ampla à qualidade do espaço urbano de 
Niterói, o programa tem como principal objetivo estimular a cultura cicloviária na cidade.

"Niterói de Bicicleta" é composto de dois principais pilares, ambos igualmente importantes e essenciais: infraestrutura cicloviária e cultura e educação cicloviárias.

a) Infraestrutura Cicloviária: Este pilar abrange todas as ações relacionadas ao planejamento de infraestrutura física adequada para que ciclistas possam se locomover e estacionar suas bicicletas com segurança e conforto. Esta infraestrutura deve atender às vocações, necessidades e limitações de cada região da cidade e às normas e aos padrões de construção e sinalização definidas no Manual de Infraestrutura Cicloviária de Niterói, este último em fase de aprovação pela Prefeitura Municipal.

b) Cultura e Educação Cicloviárias: Este pilar abrange todas as ações que buscam influenciar a cultura e o comportamento da população e visitantes de Niterói, no sentido de promover a bicicleta como meio de transporte para pequenas e médias distâncias, e para atividades de lazer. Além da organização de eventos focados na mobilidade por bicicleta, outras atividades realizadas pelo Programa Niterói de Bicicleta incluem ações de estímulo e de conscientização sobre o uso seguro da bicicleta. Disseminar informações sobre as principais regras para uma convivência harmônica no trânsito, entre motoristas, ciclistas e pedestres, também faz parte do escopo do Programa.

Até 2016 a cidade possuía 30 ciclovias e, a partir de 2017, como aparece na Figura 5, o número de vias dobrou, atingindo mais de 60 trajetos para ciclistas e pedestres, entre ciclovias, ciclofaixas e ciclo-rotas distribuídas entre as diversas regiões da cidade, interligadas entre si e a pontos de conexão com outros modais de transporte.

Esta cidade é, portanto, uma grande incentivadora deste modal e da cultura de bike, seja por deslocamento obrigatório (como o deslocamento de trabalhadores até suas empresas, ou alunos até suas instituições de ensino) ou por deslocamento livre (como passeios ao final de tarde, ou deslocamentos de final de semana). 
Figura 5. Ciclovias, ciclofaixas e bicicletários da cidade.

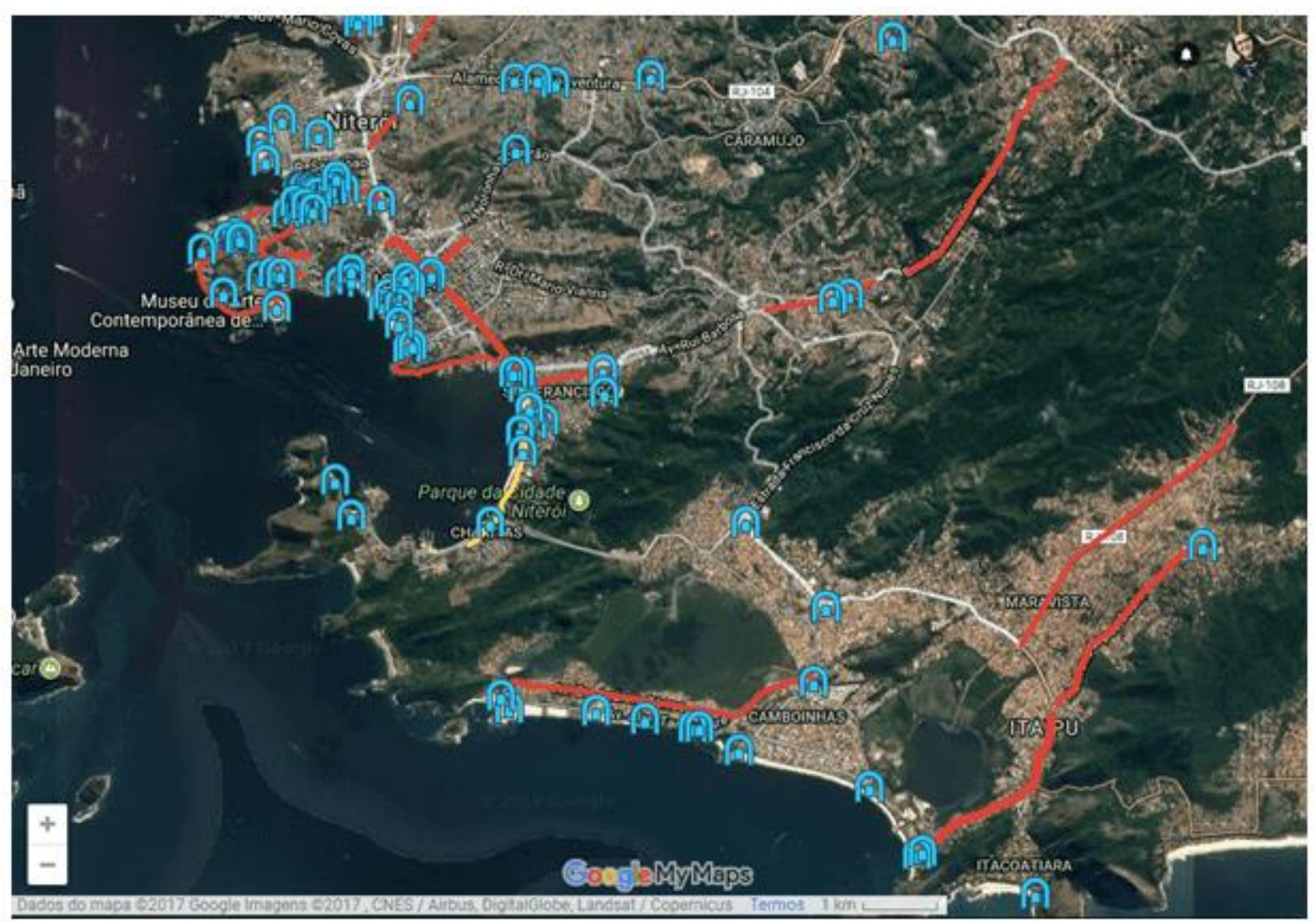

Fonte: Prefeitura de Niterói.

\subsection{A INSERÇÃO DE UMA CICLOVIA EM SÃO FRANCISCO}

São Francisco já possui uma ciclofaixa, Figura 6, isto é, uma via para pedestres e bicicletas compartilhada com veículos automotores, sem divisória física entre os meios de transporte.

A pista é localizada na faixa mais à esquerda da avenida principal do bairro, Avenida Quintino Bocaiúva, em ambos os sentidos. 
Figura 6. Ciclovia da Avenida Quintino Bocaiúva no bairro de São Francisco.

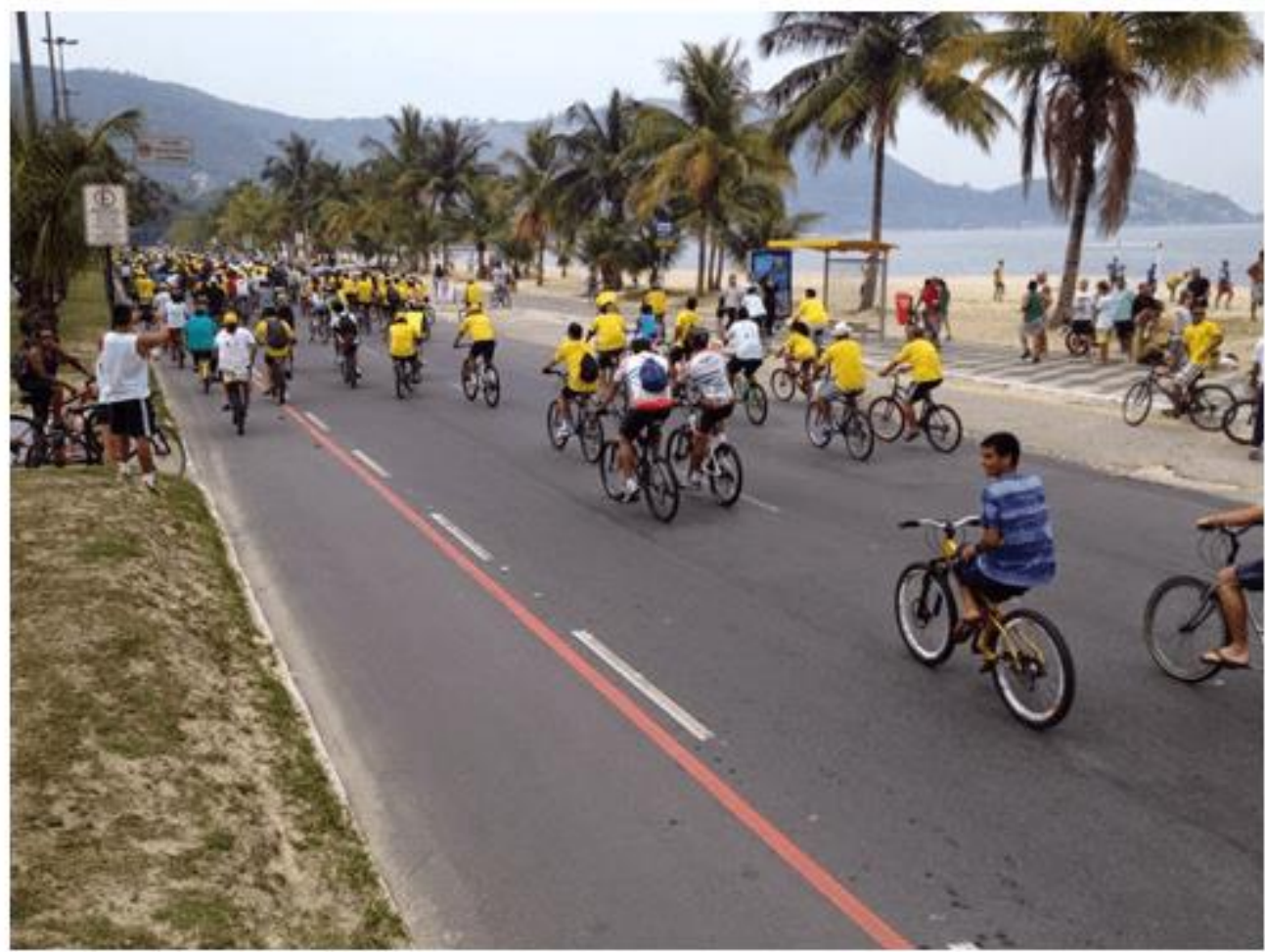

Fonte: Prefeitura de Niterói.

A escolha por uma ciclovia, em detrimento a uma ciclofaixa, se faz fundamental para evitar acidentes entre ciclistas e veículos motorizados, visto que a ciclovia, como supracitado, é a pista para bicicletas e pedestres que possui separação da pista de carros, motos e ônibus.

Foi, portanto, imprescindível para a escolha desta localização um ambiente que possuísse espaço físico para a implementação de uma ciclovia de, pelo menos, 1,5m de largura, obedecendo o MPGTU, estabelecido pelo DNIT em 2010.

A orla da praia de São Francisco possui uma calçada de, em média, 10m de largura, apresentando espaço suficiente para a construção da ciclovia. Como a Avenida possui pontos de ônibus em alguns trechos, a ciclovia deverá apresentar pequenos desvios de rota. 
Além disso, a orla do bairro, de características familiares, apresenta largo espaço para práticas de esportes, com pouca cobertura de luz - sem grande quantidade de árvores ou coberturas - combinando com a instalação de uma ciclovia fotovoltaica.

Nesta localização, com início na seta vermelha e término na seta verde da Figura 7, a pista teria uma área total de $2125 \mathrm{~m}^{2}$ composta de placas solares, sendo $850 \mathrm{~m}$ de comprimento e, 2,5m de largura.

Figura 7. Localização de ciclovia para este estudo de caso.

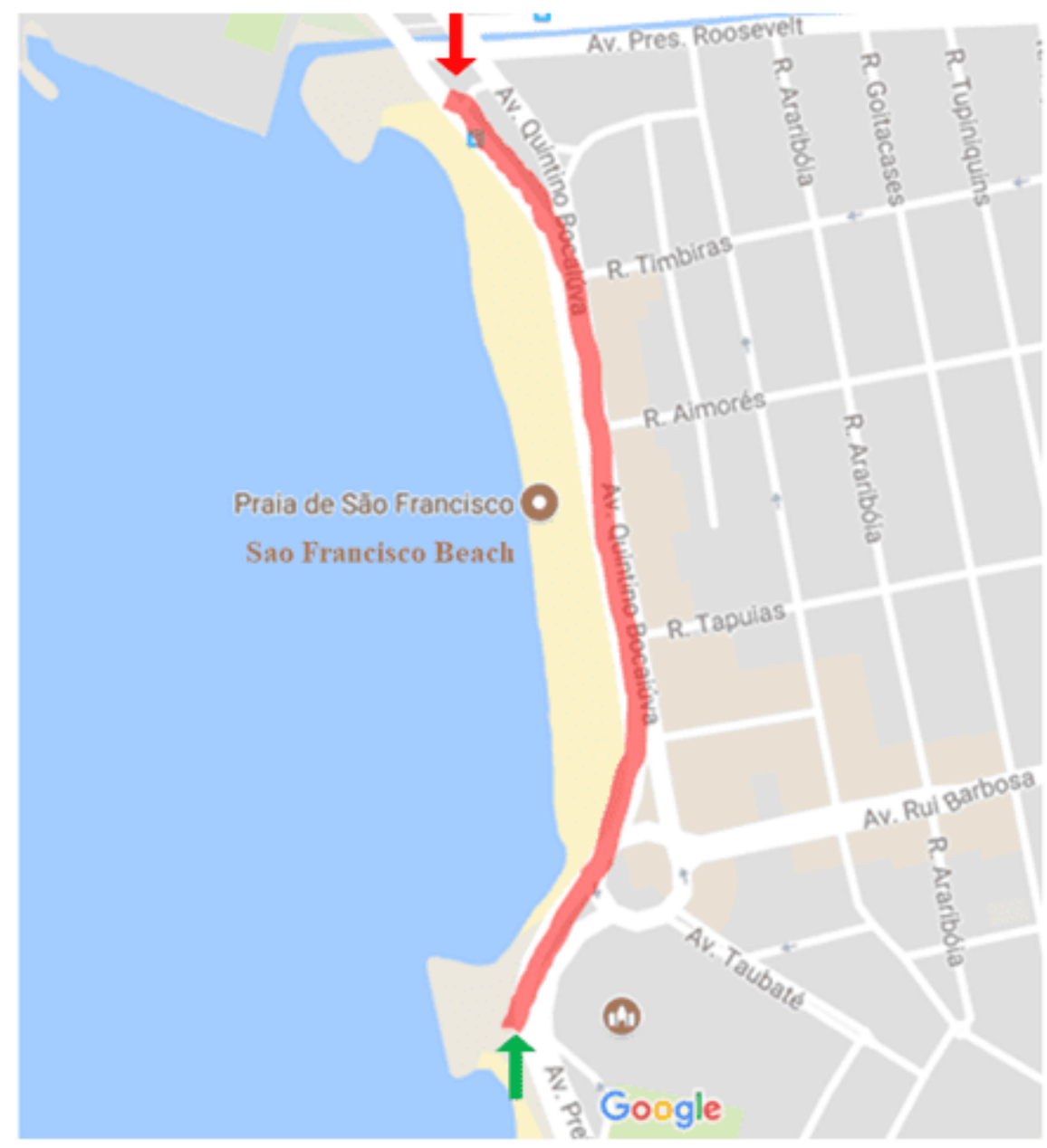

Fonte: Google Maps. 
Figura 8. Orla da praia de São Francisco, às $16 \mathrm{~h}$ de um dia de primavera, com simulação da posição da nova ciclovia.
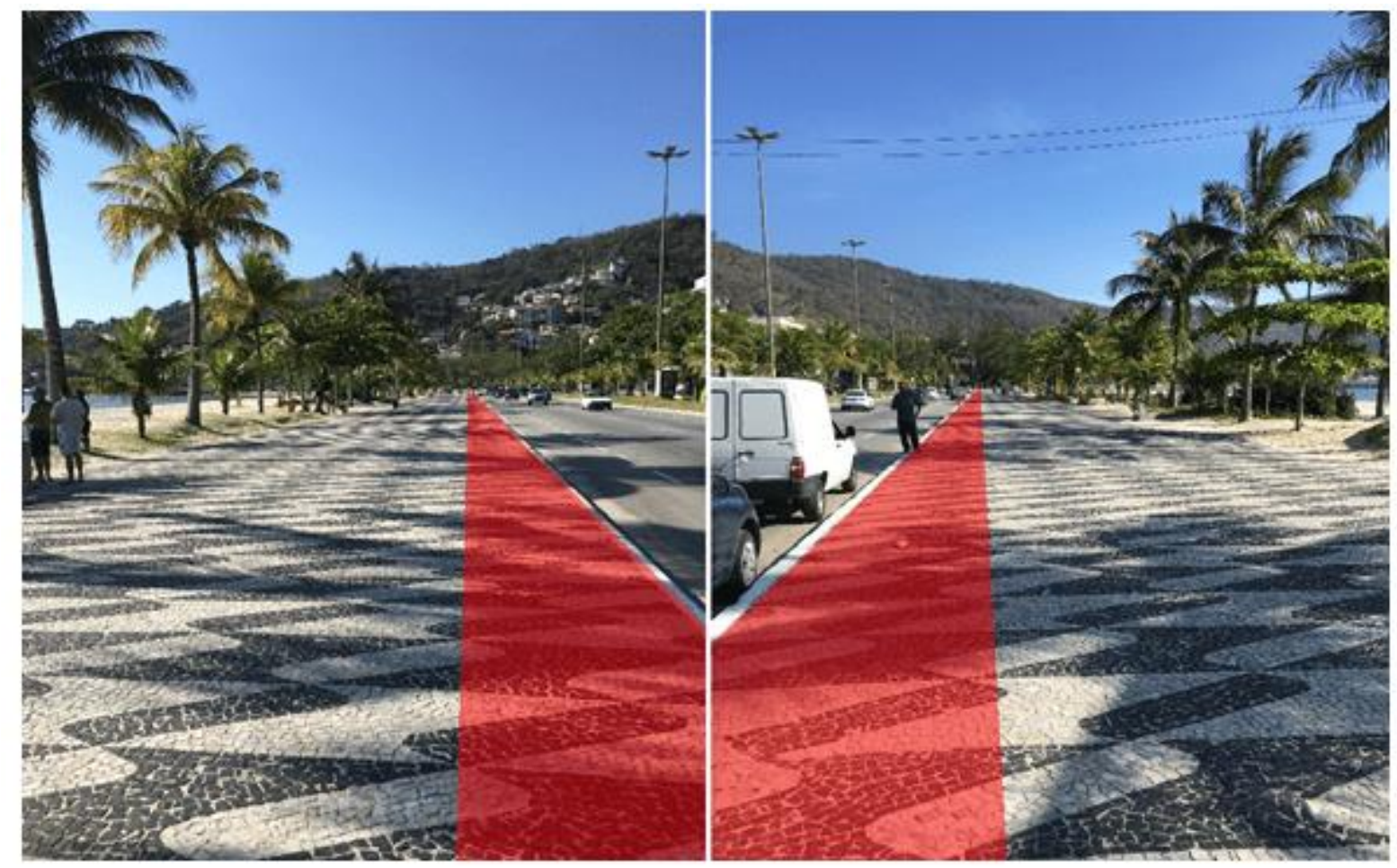

Fonte: Do autor.

Em relação aos fatores estudados, inicialmente verificou-se no website do Centro de Referência para Energia Solar e Eólica - CRESESB - Figura 9, a irradiação solar sobre a cidade de Niterói, a partir de coordenadas geográficas, de forma a analisar a energia solar da região. Esses dados de irradiação foram utilizados pelas empresas fornecedoras de sistema fotovoltaico consultadas, para determinação do ângulo de inclinação dos painéis e para o cálculo da geração de energia. 
Figura 9. Quadro de irradiação solar diária média mensal do local.

\begin{tabular}{|c|c|c|c|c|c|c|c|c|c|c|c|c|c|c|c|}
\hline \multirow[b]{2}{*}{ Angle } & \multirow{2}{*}{ Inclination } & \multicolumn{14}{|c|}{ Daily solar irradiation $\left[\mathrm{kWh} / \mathrm{m}^{2} \div\right.$ day] } \\
\hline & & Jan & Feb & Mar & Apr & May & Jun & Jul & Aug & Sep & Oct & Nov & Dec & Aver. & Delta \\
\hline Horizontal plane & $0^{*} \mathrm{~N}$ & 5,33 & 5,22 & 5,11 & 4,22 & 3,42 & 2,92 & 3,22 & 4,03 & 5,08 & 4,75 & 5,61 & 5,53 & 4,54 & 2,69 \\
\hline Latitude angle & $23^{\circ} \mathrm{N}$ & 4.83 & 4,98 & 5,26 & 4,76 & 4,18 & 3,70 & 4,03 & 4,73 & 5,44 & 4,64 & 5,14 & 4,94 & 4,72 & 1,74 \\
\hline Highest annual average & $20^{\circ} \mathrm{N}$ & 4.93 & 5,04 & 5,27 & 4,72 & 4,11 & 3,62 & 3,95 & 4,67 & 5,43 & 4,68 & 5,23 & 5,04 & 4,72 & 1,81 \\
\hline Highest monthly minimum & $43^{\circ} \mathrm{N}$ & 4,04 & 4,35 & 4.89 & 4,77 & 4,43 & 4,01 & 4,34 & 4,87 & 5,22 & 4,13 & 4,32 & 4,06 & 4,45 & 1,21 \\
\hline \multirow{2}{*}{ Ângulo } & \multirow{2}{*}{ Inclinaçāo } & \multicolumn{14}{|c|}{ Irradiaçăo solar diária média mensal [ $\mathrm{kWh} / \mathrm{m}^{2}$.dia] } \\
\hline & & Jan & Fev & Mar & Abr & Mai & Jun & Jul & Ago & Set & Out & Nov & Dez & Média & Delta \\
\hline Plano Horizontal & $0^{*} \mathrm{~N}$ & 5,33 & 5,22 & 5,11 & 4,22 & 3,42 & 2,92 & 3,22 & 4,03 & 5,08 & 4,75 & 5,61 & 5,53 & 4,54 & 2,69 \\
\hline Angulo igual a lattude & $23^{\circ} \mathrm{N}$ & 4,83 & 4,98 & 5,26 & 4,76 & 4,18 & 3,70 & 4,03 & 4,73 & 5,44 & 4,64 & 5,14 & 4,94 & 4,72 & 1,74 \\
\hline Maior média anual & $20^{\circ} \mathrm{N}$ & 4,93 & 5,04 & 5.27 & 4,72 & 4,11 & 3,62 & 3.95 & 4,67 & 5,43 & 4,68 & 5,23 & 5,04 & 4,72 & 1,81 \\
\hline Maior minimo mensal & $43^{\circ} \mathrm{N}$ & 4,04 & 4,35 & 4,89 & 4,77 & 4,43 & 4,01 & 4,34 & 4,87 & 5,22 & 4,13 & 4,32 & 4,06 & 4,45 & 1,21 \\
\hline
\end{tabular}

Fonte: CRESESB.

\subsection{A ELETRICIDADE NA CIDADE DE NITERÓI}

Desde novembro de 2016, a eletricidade fornecida no estado do Rio de Janeiro, e, portanto, na cidade de Niterói, é propriedade da companhia Enel SA, uma empresa italiana com sede em Roma que atua na geração e distribuição de energia elétrica e na distribuição de gás natural.

Com uma estrutura de 11 centros satélites em todo o estado, que funcionam como subestações, a concessionária fornece energia elétrica para todo o estado, sendo um dos centros localizado no Galo Branco, em São Gonçalo, que auxilia no fornecimento da cidade de Niterói, cidade vizinha.

Além da tarifa de consumo de energia, temos o Imposto Sobre Circulação de Mercadorias e Serviços (ICMS), que varia de acordo com a faixa de consumo de energia no mês, e também incidem sobre a conta de luz outros tributos, como PIS (Programa de Integração Social) e COFINS (Contribuição para Financiamento da Seguridade Social). Desta forma, temos as tarifas classificadas no próprio website da concessionária da seguinte forma em novembro de 2017:

\section{a) B1 - RESIDENCIAL NORMAL}

Bandeira verde: $0,68472 \mathrm{R} \$ / \mathrm{kWh}$

Bandeira amarela: 0,71363 R $\$ / \mathrm{kWh}$

RC: 35314

Disponível em: https://www.nucleodoconhecimento.com.br/engenharia-civil/paineis-fotovoltaicos 
Bandeira vermelha: $0,72809 \mathrm{R} \$ / \mathrm{kWh}$

b) B4 - ILUMINAÇÃO PUBLICA

Bandeira verde: $0,41084 \mathrm{R} \$ / \mathrm{kWh}$

Bandeira amarela: 0,43975 R $\$ / k W h$

Bandeira vermelha: $0,45421 \mathrm{R} \$ / \mathrm{kWh}$

As bandeiras são definidas pelo nível das águas nas hidrelétricas. Em épocas de chuvas e cheias, as tarifas são consideradas na faixa da bandeira verde. Já em épocas de seca, as tarifas são consideradas na faixa da bandeira vermelha. A bandeira amarela é para faixas intermediárias.

Desta forma, temos estabelecida a composição e o custo da tarifa de consumo, que levará em consideração uma média entre as tarifas da bandeira amarela e vermelha, buscando trabalhar com um cenário de margem de segurança.

\section{ANÁLISE DA VIABILIDADE ECONÔMICA}

A análise da viabilidade técnica e econômica de uma ciclovia composta de painéis fotovoltaicos em seu piso, na orla de São Francisco, na cidade de Niterói, será realizado considerando o cenário otimista. Isto significa que todos os dados considerados nos cálculos estão maximizados e extraem o melhor potencial da pista. Além disso, a marca e modelo de painel solar escolhidos para esta avaliação, baseados em compatibilidade às condições deste projeto, foi o SolaRoad Kit, da empresa SolaRoad.

De acordo com a tabela do CRESESB, como visto anteriormente, a incidência solar no mês de fevereiro em Niterói é de $5,22 \mathrm{kWh} / \mathrm{m}^{2} / \mathrm{dia}$. Esta será, portanto, a irradiação máxima a ser considerada. No entanto, as placas não conseguem absorver na totalidade a energia solar. Portanto, para maior precisão de cálculo, adota-se a máxima eficiência de placas solares de 18,5\%, definida por Dave Jones, engenheiro 
e ambientalista, grande defensor de energias renováveis, de Sydney, na Austrália, desenvolve cálculos de alguns números desse tipo de projeto, dentre eles custos, capacidade, área de implantação e incidência solar, em seu vlog EEVblog.

Realizando a perda de $81,5 \%$ desempenho, considerada por Dave Jones como a mínima possível, tem-se um desempenho de $966 \mathrm{Wh} / \mathrm{m}^{2} / \mathrm{dia}$.

$$
5,22 \frac{k W h}{m^{2} / \text { dia }} \times 0,185=966 \frac{W h}{m^{2} / \text { dia }}
$$

Também recomendado por Dave Jones, considera-se perdas de 10\% para os cabos e conversor de tensão, $20 \%$ para a espessura (10 mm) e rugosidade do vidro, e $20 \%$ para a área de superfície perdida por algum componente da placa solar ou por sujeiras, temos uma capacidade de geração de energia, no cenário otimista, de $483 \mathrm{Wh} / \mathrm{m}^{2} / \mathrm{dia}$.

$$
966 \frac{W h}{m^{2} / d i a} \times 0,5=483 \frac{W h}{m^{2} / d i a}
$$

Na pista, temos uma área de $2125 \mathrm{~m}^{2}$ e, portanto, a geração de energia total da pista será de $1026 \mathrm{kWh} / \mathrm{dia}$.

$$
483 \frac{W h}{m^{2} / d i a} \times 2125 m^{2}=1026 \frac{k W h}{d i a}
$$

O objetivo será dimensionar uma ciclovia capaz de gerar energia em postes, posicionados ao lado da pista em seus $850 \mathrm{~m}$ de comprimento, com lâmpadas de LED. A norma ABNT IEC-PAS 62612 "especifica os requisitos de desempenho para lâmpadas LED com dispositivo de controle incorporado, com tensão de alimentação até $250 \mathrm{~V}$, juntamente com os métodos de ensaio e condições mínimas requeridas, previstas para uso doméstico e iluminação geral similar, tendo: potência nominal de 60W; tensão nominal de até 250V C.A. ou C.C.; e bases da lâmpada de acordo com 
ABNT NBR IEC 62560”. Desta forma, o LED utilizado na iluminação pública deverá seguir 3 critérios mínimos:

a) Temperatura da cor: $3.700 \mathrm{~K}$ e $4300 \mathrm{~K}$;

b) Eficiência luminosa: mínima de $100 \mathrm{~lm} / \mathrm{W}$;

c) Potência: 60 W.

Desta forma, a iluminação mínima de um poste é de $60 \mathrm{~W}$ e o espaçamento entre os postes recomendando pela NTD-08 - Critérios de Projetos de Redes de Distribuição Aéreas Urbanas - Classes 15 e 36,2kV é de 30 a 40m. Portanto, para a pista desta monografia será levantada a demanda de 29 postes, totalizando 25,8 kWh/dia. Foram consideradas $11 \mathrm{~h}$ de iluminação (de 19h30 às 6h30) de acordo com o website Sunset and Sunrise, que fornece os horários de nascer e pôr do sol em qualquer dia do ano, para qualquer localização. Desta forma, Niterói possui, em fevereiro, um nascer do sol às 6 h30 e um pôr do sol às $19 h 30$.

\section{$60 \mathrm{~W} \times 29$ postes $\times 11 \mathrm{~h}=19,2 \mathrm{kWh} /$ dia}

Com o valor de consumo médio de energia (19,2 kWh/dia) e a geração de energia da pista (1026 kWh/dia), fica nítido que se apenas estes fatores fossem levados em consideração, a pista seria 100\% iluminada pela geração de energia causada pelos painéis fotovoltaicos e ainda seria possível armazenar a energia restante para abastecer outros pontos de iluminação público. Desta forma, o próximo passo será compreender se esta geração de energia poderia auxiliar no abastecimento de energia de residências de classe média brasileira, Figura 10. 
Figura 10. Quadro de consumo médio de residência brasileira.

\begin{tabular}{|c|c|c|c|}
\hline \multicolumn{4}{|c|}{ Monthly consumption } \\
\hline \multicolumn{4}{|c|}{ House for 4 people } \\
\hline . & & & $\begin{array}{c}\text { Consumption } \\
(k w \times h)\end{array}$ \\
\hline \multirow[b]{2}{*}{ Living room } & Lighting & $0,2 \mathrm{~kW} \times 2 \mathrm{~h} / \mathrm{dia} \times 30 \mathrm{dias}$ & 12,0 \\
\hline & Power outlets & $0,4 \mathrm{~kW} \times 3 \mathrm{~h} / \mathrm{dia} \times 30$ dias $(\mathrm{TV})$ & 36,0 \\
\hline \multirow{2}{*}{ Bedroom 1} & Lighting & $0,1 \mathrm{~kW} \times 1 \mathrm{~h} / \mathrm{dia} \times 30 \mathrm{dias}$ & 3,0 \\
\hline & Power outlets & $0,5 \mathrm{~kW} \times 0,2 \mathrm{~h} / \mathrm{dia} \times 30$ dias & 3,0 \\
\hline \multirow{2}{*}{ Bedroom 2} & Lighting & $0,1 \mathrm{~kW} \times 1 \mathrm{~h} / \mathrm{dia} \times 30 \mathrm{dias}$ & 3,0 \\
\hline & Power outlets & $0,4 \mathrm{~kW} \times 0,2 \mathrm{~h} / \mathrm{dia} \times 30$ dias & 2,4 \\
\hline \multirow{6}{*}{ Kitchen } & Lighting & $0,1 \mathrm{~kW} \times 3 \mathrm{~h} / \mathrm{dia} \times 30$ dias & 9,0 \\
\hline & Power outlets & $0,3 \mathrm{~kW} \times 0,5 \mathrm{~h} / \mathrm{dia} \times 30$ dias & 4,5 \\
\hline & Refrigerator & $0,4 \mathrm{~kW} \times 6 \mathrm{~h} / \mathrm{dia} \times 30$ dias & 72,0 \\
\hline & Freezer & $0,5 \mathrm{~kW} \times 6 \mathrm{~h} / \mathrm{dia} \times 30 \mathrm{dias}$ & 90,0 \\
\hline & Dishwasher & $2,2 \mathrm{~kW} \times 1 \mathrm{~h} / \mathrm{dia} \times 30$ dias & 66,0 \\
\hline & Toaster & $3 \mathrm{~kW} \times 1 \mathrm{~h} / \mathrm{dia} \times 30$ dias & 90,0 \\
\hline \multirow{3}{*}{ Laundry Room } & Lighting & $0,1 \mathrm{~kW} \times 0,5 \mathrm{~h} / \mathrm{dia} \times 30$ dias & 1,5 \\
\hline & Washer & $0,6 \mathrm{~kW} \times 6 \mathrm{~h} / \mathrm{sem} . \times 4 \mathrm{sem}$ & 9,6 \\
\hline & Iron & $0,6 \mathrm{~kW} \times 4 \mathrm{~h} / \mathrm{sem} . \times 4 \mathrm{sem}$. & 14,4 \\
\hline \multirow{4}{*}{ Bathroom } & Lighting & $0,1 \mathrm{~kW} \times 1 \mathrm{~h} / \mathrm{dia} \times 30$ dias & 3,0 \\
\hline & Power outlets & $0,1 \mathrm{~kW} \times 0,1 \mathrm{~h} / \mathrm{dia} \times 30$ dias & 0,3 \\
\hline & Shower & $4,0 \mathrm{~kW} \times 1 \mathrm{~h} / \mathrm{dia} \times 30 \mathrm{dias}$ & 120,0 \\
\hline & & TOTAL & 539.7 \\
\hline
\end{tabular}

\begin{tabular}{|c|c|c|c|}
\hline \multicolumn{4}{|c|}{ Estimativa de consumo mensal } \\
\hline \multicolumn{4}{|c|}{ Unidade residencial de uma familia com 4 pessoas } \\
\hline Ambiente & & Uso & $\begin{array}{l}\text { Consumo } \\
(\mathrm{kW} \times \mathrm{h})\end{array}$ \\
\hline \multirow{2}{*}{ SALA } & iluminação & $0,2 \mathrm{~kW} \times 2 \mathrm{~h} / \mathrm{dia} \times 30$ dias & 12,0 \\
\hline & tomadas & $0,4 \mathrm{~kW} \times 3 \mathrm{~h} / \mathrm{dia} \times 30$ dias (TV) & 36,0 \\
\hline DORMITÓRIO 1 & tomadas & $0,5 \mathrm{~kW} \times 0,2 \mathrm{~h} / \mathrm{dia} \times 30$ dias & 3,0 \\
\hline \multirow{2}{*}{ DORMITÓRIO 2} & iluminação & $0,1 \mathrm{~kW} \times 1 \mathrm{~h} / \mathrm{dia} \times 30$ dias & 3,0 \\
\hline & tomadas & $0,4 \mathrm{~kW} \times 0,2 \mathrm{~h} / \mathrm{dia} \times 30$ dias & 2,4 \\
\hline \multirow{3}{*}{ COZINHA } & iluminação & $0,1 \mathrm{~kW} \times 3 \mathrm{~h} / \mathrm{dia} \times 30$ dias & 9,0 \\
\hline & tomadas & $0,3 \mathrm{~kW} \times 0,5 \mathrm{~h} / \mathrm{dia} \times 30$ dias & 4,5 \\
\hline & torneira & $3 \mathrm{~kW} \times 1 \mathrm{~h} / \mathrm{dia} \times 30 \mathrm{dias}$ & 90,0 \\
\hline \multirow{3}{*}{ ÁREA DE SERVIÇO } & iluminação & $0,1 \mathrm{~kW} \times 0,5 \mathrm{~h} / \mathrm{dia} \times 30$ dias & 1,5 \\
\hline & máq. lav. roup. & $0,6 \mathrm{~kW} \times 6 \mathrm{~h} / \mathrm{sem} . \times 4 \mathrm{sem}$ & 9,6 \\
\hline & ferro & $0,6 \mathrm{~kW} \times 4 \mathrm{~h} / \mathrm{sem} . \times 4 \mathrm{sem}$. & 14,4 \\
\hline \multirow{4}{*}{ BANHEIRO } & iluminação & $0,1 \mathrm{~kW} \times 1 \mathrm{~h} / \mathrm{dia} \times 30$ dias & 3,0 \\
\hline & tomadas & $0,1 \mathrm{~kW} \times 0,1 \mathrm{~h} / \mathrm{dia} \times 30$ dias & 0,3 \\
\hline & chuveiro & $4,0 \mathrm{~kW} \times 1 \mathrm{~h} / \mathrm{dia} \times 30 \mathrm{dias}$ & 120,0 \\
\hline & & TOTAL * & 539.7 \\
\hline
\end{tabular}

Fonte: Site Engenharia. 
De acordo com o website Site Engenharia, a estimativa de consumo mensal para uma unidade residencial de uma família com 4 pessoas é de $539 \mathrm{kWh} / \mathrm{mês}$, isto é, 18 $\mathrm{kWh} / \mathrm{dia}$.

É possível ver que ao desconsiderar o consumo de eletricidade da ciclovia, temos um potencial energético restante de 1006,8 kWh/dia.

$$
1026 \frac{k W h}{\text { dia }}-19,2 \frac{k W h}{\text { dia }}=1006,8 \frac{\mathrm{kWh}}{\text { dia }}
$$

Com esta capacidade restante, a pista será capaz de alimentar 55 residências de classe média (990kWh/dia), restando apenas um potencial energético de 16,8 kWh/dia não utilizado.

$$
1006,8 \frac{\mathrm{kWh}}{\text { dia }}-\left(55 \text { casas } x 18 \frac{\mathrm{kWh}}{\text { dia }}\right)=16,8 \frac{\mathrm{kWh}}{\text { dia }}
$$

Portanto, a pista terá um consumo final de 1009,2 kWh/dia, somando o consumo exigido pelos 29 postes de iluminação ao consumo exigido pelas 55 casas.

$$
19,2 \frac{\mathrm{kWh}}{\text { dia }}+990 \frac{\mathrm{kWh}}{\mathrm{dia}}=1009,2 \frac{\mathrm{kWh}}{\mathrm{dia}}
$$

No entanto, a relação financeira entre o consumo necessário para os postes e casas e o custo de compra dos painéis fotovoltaicos se torna fundamental. Nesta avaliação, serão desconsiderados valores de instalação da pista e dos postes de luz, bem como qualquer taxa de importação do produto, depreciação e manutenção do equipamento, devido à ausência de informações precisas quanto a estes valores.

Desta forma, o próximo passo será realizar um comparativo entre o custo de investimento desta pista e o custo desta geração de energia através da concessionária.

O consumo de 1009,2 kWh/dia terá um custo de 722,23 R $\$$ /dia de acordo com o padrão de cobrança da concessionária Enel. 


$$
\left[\left(19,2 \frac{k W h}{\text { dia }} \times 0,45 \frac{R \$}{k W h}\right)+\left(18 \frac{k W h}{d i a} \times 0,72 \frac{R \$}{k W h} \times 55 \text { casas }\right)\right] \times 365 \text { dias }=263.615,20 \frac{R \$}{\text { ano }}
$$

O custo de consumo em um ano será, portanto, de $\mathrm{R} \$ 263.615,20$.

Figura 11. SolaRoad Kit.

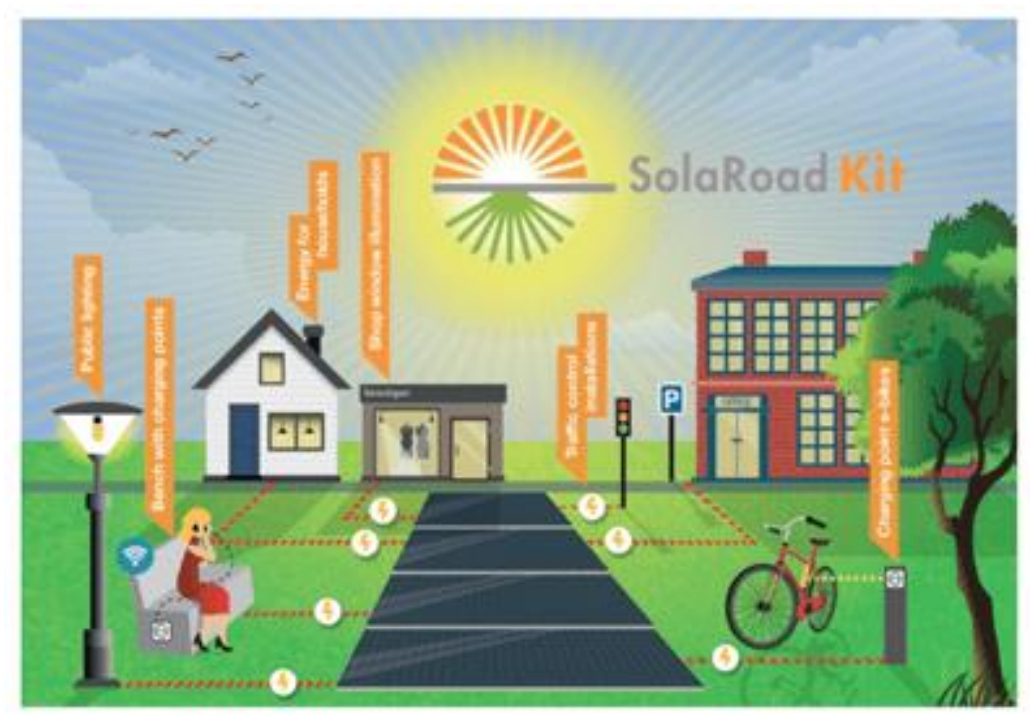

Fonte: SolaRoad.

O custo da pista de $70 \mathrm{~m}$ da SolaRoad, para o protótipo, foi de 3 milhões de euros. No entanto, a partir de 2016, a empresa passou a produzir os painéis em larga escala, comercializando o SolaRoad Kit para instalação em pistas de pedestres e ciclovias.

O preço do Kit com 4 painéis solares de 2,5 x 3,5 m é estimado em 78 mil euros, de acordo com Jan-Hendrik Kremer, o representante comercial da empresa. No caso da pista deste projeto, que possui um comprimento de $850 \mathrm{~m}$, seriam necessários $15 \mathrm{Kits}$, totalizando um investimento inicial de 4,74 milhões de euros.

$$
\frac{850 \mathrm{~m}}{(3,5 \mathrm{~m} \times 4)} \times 78.000 €=€ 4,74 \text { milhòes }
$$

Em 9 de dezembro de 2017, o câmbio entre Euro e Real era de $€ 1,00$ para $R \$ 3,88$. Desta forma, o preço dos 15 kits seria de $R \$ 18,37$ milhões. 


\section{$€ 4.735 .714,29 x \quad R \$ 3,88=\mathrm{R} \$ 18,37$ milhões}

Se nenhum outro custo fosse considerado no projeto, exceto os 18,37 milhões de reais, teríamos um equilíbrio financeiro - isto é, o custo de implementação seria igual ao preço pago para este consumo - em 70 anos.

$$
\frac{R S 18.374 .571,45}{263.615,20 \frac{R S}{\text { ano }}}=70 \text { anos }
$$

Como mencionado, este valor desconsidera: (a) os custos de manutenção do material; (b) os custos de instalação e construção da pista; e (c) os custos de depreciação dos equipamentos e dos componentes de iluminação da pista, dentre outros valores que, apesar de significativos, percentualmente podem ser desprezados quando comparados ao investimento inicial deste projeto (18,37 milhões de reais) e do tempo de payback (70 anos), que só teria aumento com o acréscimo destes fatores.

Este payback propriamente calculado, é mais do que o dobro do tempo regular de vida útil do equipamento esperado pela SolaRoad, de aproximadamente 30 anos. Dessa forma, esta projeção é considerada inviável.

\section{CONCLUSÃO}

O uso da bicicleta apresenta benefícios ao indivíduo e à comunidade ao seu redor, reduzindo os gastos governamentais com saúde e os custos de medidas paliativas para a poluição aérea e sonora, acidentes e mudanças climáticas pela emissão de gases. Além disso, a troca de automóveis por bicicletas reduz o espaço e os investimentos alocados para estacionamentos além de estimular a construção e a preservação de espaços voltados para o convívio humano nas comunidades.

Desde 1970, países do leste Europeu como Alemanha e Holanda adotam medidas de mobilidade sustentável, o que faz com que a bicicleta nestes países seja um importante meio de locomoção. As ações realizadas por estes governantes têm como objetivo a melhoria das condições de vida e de deslocamento dos ciclistas, bem como 
a superação de barreiras do uso do veículo, que envolvem modificações na infraestrutura das ruas e programas relativos à educação no trânsito.

No Brasil, este pensamento sustentável e o incentivo aos meios de locomoção limpos estão começando a ganhar força apenas nas duas últimas décadas, o que torna a produção de painéis solares pouco disseminada e, por consequência, muito custosa. Apesar de existirem tais incentivos conhecidos - como o desconto em contas de luz para usuários de painéis solares -, não é possível encontrar qualquer tipo de norma ou legislação que garanta qualquer tipo de remuneração por custo ambiental. Isto é, não há registro governamental que garanta retorno financeiro ao usuário - seja público ou privado - de painéis solares por colaborar com a preservação do meio ambiente.

Desta forma, é possível ver através do estudo econômico deste trabalho que a realização de uma ciclovia composta de painéis solares em seu piso depende obrigatoriamente da importação de tais materiais - devido à ausência de produção em solo brasileiro.

Apesar da inviabilidade econômica identificada neste trabalho para a realização de um projeto deste porte, existem possibilidades alternativas mais viáveis para a execução de uma ciclovia capaz de gerar energia, como, (a) a construção de uma cobertura de painéis solares sobre este modal, que poderá ser realizada devido a produção de todos os equipamentos envolvidos nesta solução em solo brasileiro, tornando o custo do projeto muito mais baixo; ou (b) a construção de postes ao longo da ciclovia, onde cada poste terá uma placa solar acoplada a si e, desta forma, será capaz de absorver energia para se auto abastecer durante o período noturno. Um exemplo desta segunda opção é o Arco Metropolitano no Rio de Janeiro da Figura 12, que conecta a Manilha (São Gonçalo/RJ) ao Porto de Itaguaí (Itaguaí/RJ).

Portanto, há a reafirmação da justificativa para a elaboração deste projeto: no século 21 será papel fundamental do engenheiro a preocupação com a segurança de uma estrutura, bem como com a sua condição de sustentabilidade. Deverá ser de responsabilidade do engenheiro realizar somente projetos que visem a garantia de um futuro sustentável para as próximas gerações. A energia solar é a energia limpa com 
maior capacidade de geração de energia e, paralelo a isso, o modal de bicicletas é um dos mais limpos e eficientes da atualidade. Isto posto, não será uma surpresa vermos estas duas inovações cada vez mais latentes em nossa sociedade.

Figura 12. Arco Metropolitano do Rio de Janeiro com painéis solares acoplados em postes.

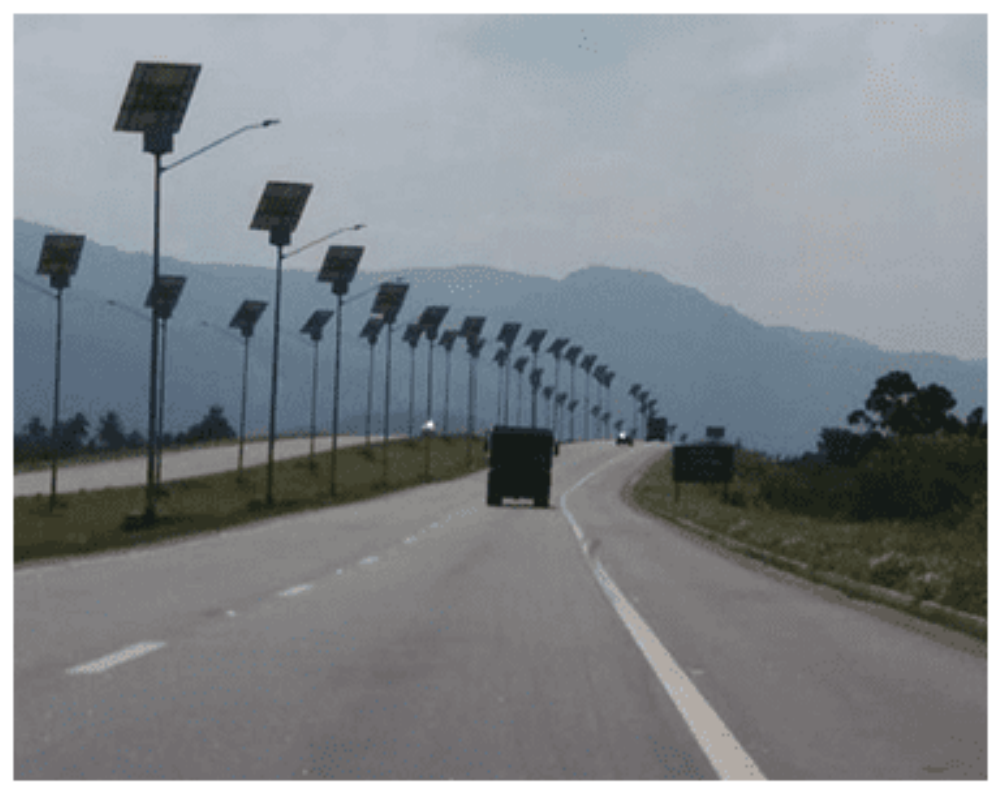

Fonte: Globo.

\section{REFERÊNCIAS}

ANTP. Relatório Geral de Mobilidade urbana. Sistema de Informações da Mobilidade Urbana. Disponível em <http://filesserver.antp.org.br/_5dotSystem/download/dcmDocument/2013/ 04/11/ 19492C7F-68AE-416B-91C2-42D2A3774D81.pdf>. Acesso em 24 de setembro de 2017.

BARATTO, Romulo. 100 Melhores Cidades do Brasil para Viver. Disponível em $<$ http://www. archdaily.com.br/br/870676/as-100-melhores-cidades-do-brasil-paraviver>. Acesso em 21 de outubro de 2017. 
BOARETO, Renato. A bicicleta e as cidades: como inserir a bicicleta na política de mobilidade urbana / organização. Disponível em $<$ http://www.energiaeambiente.org.br/wp-content/uploads/2015/ 09/A-bicicleta-e-ascidades.pdf>. Acesso em 24 de setembro de 2017.

BRASIL. Departamento Nacional de Infraestrutura de Transportes. Diretoria Executiva. Instituto de Pesquisas Rodoviárias. Manual de projeto geométrico de travessias urbanas - Rio de Janeiro, 2010.

BRASIL. Pesquisa Origem e Destino 2007 Região Metropolitana de São Paulo. Disponível em <http://www.metro.sp.gov.br/metro/arquivos/OD2007/sinteseod2007.pdf>. Acesso em 24 de setembro de 2017.

CRESESB. Centro de Referência das Energias Solar e Eólica. Disponível em < http://www. cresesb.cepel.br/index.php?section=sundat $\mathrm{A}$. Acesso em 9 de novembro de 2017.

ECOMONTES. Energia Solar. Disponível em <http://ecomontes.com.br/afinal-o-quee-energia-solar-saiba-tudo-aqui/>. Acesso em 16 de dezembro de 2017.

ENEL. Taxas, Tarifas e Impostos. Disponível em $<$ https://www.eneldistribuicao.com.br/rj/Taxas ETarifas.aspx>. Acesso em 14 de dezembro de 2017.

FIRJAN. Índice FIRJAN de Gestão Fiscal. Disponível em <www.firjan.com.br/ifgf>. Acesso em 21 de outubro de 2017.

IFRN. Projeto Integrador. Disponível em < http://educenergiahidreletrica.blogspot.com.br/ 2009/06/vantagens.html>. Acesso em 15 de outubro de 2017.

NATIONAL GEOGRAPHIC, ENVIRONMENTAL PROTECTION AGENCY, US GEOLOGICAL SUREVY, GLOBAL RELEAF. Benefícios ao meio ambiente, 2014. 
NIJKAMP, Peter. Social Change and Sustainable Transport. Indiana University Press, 2002.

O FLUMINENSE. Niterói é a quarta melhor cidade do Brasil em qualidade de vida para idosos. Disponível em <http://www.ofluminense.com.br/pt-br/cidades/niter\%C3\%B3i\%C3\%A9-quarta-melhor-cidade-do-brasil-em-qualidade-de-vida-para-idosos>. Acesso em 21 de outubro de 2017.

OECD. Key Transport Statistics - International Transport Forum. Disponível em $<$ https://www.itf-oecd.org/sites/default/files/docs/key-transport-statistics-2017.pdf>. Acesso em 24 de setembro de 2017.

OXFORD UNIVERSITY - CENTRE FOR THE ENVIRONMENT. Environmental Change Institute. Disponível

em

$<$ http://www.eci.ox.ac.uk/research/energy/downloads/ countrypictures/ cp_netherlands.pdf $>$. Acesso em 4 de novembro de 2017.

PNUD. Atlas do Desenvolvimento Humano. Disponível em < http://www.br.undp.org/ content/brazil/pt/home/>. Acesso em 15 de outubro de 2017.

SITE ENGENHARIA. Estimativa de Consumo Mensal para Unidade Familiar Brasileira. Disponível em <http://www.sitengenharia.com.br/tabelaenergia.htm>. Acesso em 9 de dezembro de 2017.

SOLAROAD. Ciclovia de painéis solares no piso (Amsterdam, Holanda). Disponível em < www.solaroad.nl>. Acesso em 21 de outubro de 2017.

Enviado: Julho, 2019.

Aprovado: Agosto, 2019. 